\title{
Alemtuzumab improves preexisting disability in active relapsing-remitting MS patients
}

\section{OPEN}

Gavin Giovannoni, MD, $\mathrm{PhD}$

Jeffrey A. Cohen, MD

Alasdair J. Coles, MD,

$\mathrm{PhD}$

Hans-Peter Hartung,

$\mathrm{MD}, \mathrm{PhD}$

Eva Havrdova, MD, PhD

Krzysztof W. Selmaj,

$\mathrm{MD}, \mathrm{PhD}$

David H. Margolin, MD, $\mathrm{PhD}$

Stephen L. Lake, ScD

Susan M. Kaup, PhD, MBA

Michael A. Panzara, MD, $\mathrm{MPH}$

D. Alastair S. Compston, $\mathrm{MD}, \mathrm{PhD}$

On behalf of the CAREMS II Investigators

Correspondence to

Dr. Giovannoni:

g.giovannoni@qmul.ac.uk

\section{Editorial, page 1966}

\section{Supplemental data} at Neurology.org

\section{ABSTRACT}

Objective: To characterize effects of alemtuzumab treatment on measures of disability improvement in patients with relapsing-remitting multiple sclerosis (RRMS) with inadequate response ( $\geq 1$ relapse) to prior therapy.

Methods: Comparison of Alemtuzumab and Rebif Efficacy in Multiple Sclerosis (CARE-MS) II, a 2-year randomized, rater-blinded, active-controlled, head-to-head, phase 3 trial, compared efficacy and safety of alemtuzumab $12 \mathrm{mg}$ with subcutaneous interferon- $\beta$ - 1 a (SC IFN- $\beta-1 \mathrm{a}) 44 \mu \mathrm{g}$ in patients with RRMS. Prespecified and post hoc disability outcomes based on Expanded Disability Status Scale (EDSS), Multiple Sclerosis Functional Composite (MSFC), and Sloan lowcontrast letter acuity (SLCLA) are reported, focusing on improvement of preexisting disability in addition to slowing of disability accumulation.

Results: Alemtuzumab-treated patients were more likely than SC IFN- $\beta$-1a-treated patients to show improvement in EDSS scores ( $p<0.0001$ ) on all 7 functional systems. Significantly more alemtuzumab patients demonstrated 6-month confirmed disability improvement. The likelihood of improved vs stable/worsening MSFC scores was greater with alemtuzumab than SC IFN- $\beta$ - 1 a ( $p=0.0300$ ); improvement in MSFC scores with alemtuzumab was primarily driven by the upper limb coordination and dexterity domain. Alemtuzumab-treated patients had more favorable changes from baseline in SLCLA (2.5\% contrast) scores ( $p=0.0014)$ and MSFC + SLCLA composite scores ( $p=0.0097$ ) than SC IFN- $\beta-1$ a-treated patients.

Conclusions: In patients with RRMS and inadequate response to prior disease-modifying therapies, alemtuzumab provides greater benefits than SC IFN- $\beta-1$ a across several disability outcomes, reflecting improvement of preexisting disabilities.

Classification of evidence: This study provides Class I evidence (based on rater blinding and a balance in baseline characteristics between arms) that alemtuzumab modifies disability measures favorably compared with SC IFN- $\beta-1$ a. Neurology ${ }^{\circledR}$ 2016;87:1985-1992

\section{GLOSSARY}

9-HPT = 9-Hole Peg Test; ANCOVA = analysis of covariance; AUC = area under the curve; CARE-MS II = Comparison of Alemtuzumab and Rebif Efficacy in Multiple Sclerosis II; CDI = confirmed disability improvement; CDW = confirmed disability worsening; DMT = disease-modifying therapy; EDSS = Expanded Disability Status Scale; GA = glatiramer acetate; $\mathbf{H R}=$ hazard ratio; IFN- $\boldsymbol{\beta}-\mathbf{1} \mathbf{a}=$ interferon- $\beta-1 \mathrm{a} ; \mathbf{M S}=$ multiple sclerosis; $\mathbf{M S F C}=$ Multiple Sclerosis Functional Composite; OR = odds ratio; RRMS = relapsing-remitting multiple sclerosis; $\mathbf{S C}=$ subcutaneous; $\mathbf{S L C L A}=$ Sloan low-contrast letter acuity.

Limiting disability is a major objective in multiple sclerosis (MS) care. Most disease-modifying therapies (DMTs) approved for relapsing-remitting MS (RRMS) delay confirmed disability worsening (CDW) vs placebo, based on Expanded Disability Status Scale (EDSS) outcomes. ${ }^{1-7}$ Interest is growing in aiming for confirmed disability improvement (CDI), a higher

From Queen Mary University of London (G.G.), Barts and The London School of Medicine, UK; Mellen Center (J.A.C.), Cleveland Clinic, OH; Department of Clinical Neurosciences (A.J.C., D.A.S.C.), University of Cambridge, UK; Department of Neurology and Center for Neuropsychiatry (H.-P.H.), Heinrich-Heine University, Düsseldorf, Germany; Department of Neurology and Center for Clinical Neuroscience (E.H.), First Medical Faculty, Charles University in Prague, Czech Republic; Department of Neurology (K.W.S.), Medical University of Łódź, Poland; Sanofi Genzyme (D.H.M., S.L.L., M.A.P.), Cambridge, MA; and Evidence Scientific Solutions (S.M.K.), Philadelphia, PA (at the time the work was conducted). Coinvestigators are listed at Neurology.org.

Go to Neurology.org for full disclosures. Funding information and disclosures deemed relevant by the authors, if any, are provided at the end of the article. The Article Processing Charge was paid by Sanofi Genzyme.

This is an open access article distributed under the terms of the Creative Commons Attribution-NonCommercial-NoDerivatives License 4.0 (CC BY-NC-ND), which permits downloading and sharing the work provided it is properly cited. The work cannot be changed in any way or used commercially. 
standard for therapeutic efficacy than merely slowing disability accumulation. Because disability is a primary contributor to the burden of $\mathrm{MS},{ }^{8-10}$ restoring function in patients with previously acquired neurologic impairments may lead to improved long-term prognosis, greater productivity and quality of life, and reduced economic costs.

CDI is a metric reflecting durable and clinically meaningful EDSS score changes. In the phase 2 trial of alemtuzumab for RRMS (CAMMS223; NCT00050778) and the phase 3 Comparison of Alemtuzumab and Rebif Efficacy in Multiple Sclerosis II (CARE-MS II; NCT00548405) trial, CDI was more likely in alemtuzumab-treated patients than those receiving subcutaneous interferon- $\beta-1 \mathrm{a}$ (SC IFN- $\beta-1 a) .{ }^{11,12}$ In CARE-MS II, alemtuzumab was also associated with significantly greater improvement in mean EDSS and Multiple Sclerosis Functional Composite (MSFC) scores vs SC IFN- $\beta-1 \mathrm{a} .{ }^{12}$

The EDSS is an important tool in assessing disability, but is heavily weighted toward ambulation and relatively insensitive to other aspects of disability. ${ }^{13,14}$ We therefore analyzed disability using EDSS-based and non-EDSSbased methods. The results of these prespecified outcomes and post hoc analyses from CARE-MS II more fully characterize the effects of alemtuzumab on disability in patients with RRMS than those published previously, ${ }^{12}$ and indicate potential for long-term improvement.

METHODS Patients and study design. Methods have been published elsewhere. ${ }^{12}$ CARE-MS II was a 2-year, randomized, rater-blinded, active comparator-controlled, head-to-head, trial of alemtuzumab (Lemtrada; Sanofi Genzyme, Cambridge, MA; 12 $\mathrm{mg} /$ day on 5 consecutive days at month 0 and on 3 consecutive days at month 12) vs SC IFN- $\beta$-1a (Rebif; EMD Serono, Rockland, MA; $44 \mu \mathrm{g} 3$ times weekly) in patients with RRMS with inadequate response to prior DMTs $(\geq 1$ relapse during IFN- $\beta$ or glatiramer acetate $[\mathrm{GA}]$ treatment [received for $\geq 6$ months]). ${ }^{12}$

Disability assessment procedures. Differences in study drug administration and unique adverse event profiles precluded effective double-blinding. Blinded raters performed EDSS assessments at baseline, every 3 months, and when relapse was suspected. EDSS score changes of $\geq 1$ point, confirmed over 3 or 6 months or longer, are accepted as clinically meaningful. ${ }^{15}$

Raters administered the MSFC ${ }^{16} 3$ times before baseline to attenuate practice effects, then every 6 months. MSFC is a multidimensional instrument comprising quantitative tests of neurologic performance in 3 critical domains: upper limb coordination and dexterity (9-Hole Peg Test [9-HPT], raw score measured in seconds); ambulation (25-Foot Timed Walking test, raw score measured in seconds); and cognitive function (Paced Auditory Serial Addition Test [PASAT]-3, raw score measured as number of correct responses). MSFC component scores were standardized by conversion into $Z$ scores (SD units from mean population baseline score) and averaged to a summary MSFC score; increased MSFC scores indicate improvement. ${ }^{17}$ Changes from baseline of $\geq 15 \%$ or $\geq 20 \%$ on $\geq 1$ MSFC component score may be considered clinically meaningful. ${ }^{18}$

Visual function was assessed every 6 months using binocular Sloan low-contrast letter acuity (SLCLA). Sloan charts display alphabetic characters with various visual contrast differentials $(1.25 \%, 2.5 \%$, and $100 \%$, ranging from light gray to black); scores represent the number of correctly identified letters (maximum 70). Increased or decreased SLCLA counts of $\geq 5$ letters at $100 \%$ contrast, or $\geq 7$ letters at $1.25 \%$ and $2.5 \%$ contrast, were defined as clinically meaningful improvements or decrements, respectively, as per prior MS studies. ${ }^{19}$ SLCLA was not assessed at Russian and Ukrainian sites because Latin alphabetic characters in Sloan charts may be unfamiliar in these countries. SLCLA was normalized in the same manner as MSFC components. Patients were also assessed using the 4-component, MSFC plus SLCLA score incorporating $Z$ scores from binocular, $1.25 \%$ contrast testing. ${ }^{20}$ Previous work showed that $1.25 \%$ contrast provided the greatest capacity to detect visual dysfunction in patients with MS vs healthy controls. ${ }^{20}$

Endpoints. The following CARE-MS II tertiary endpoints were assessed: time to CDI ( $\geq 1.0$-point EDSS decrease from baseline sustained for $\geq 3$ or $\geq 6$ months, in patients with baseline score $\geq 2.0$ ); proportion worsened ( $\geq 0.5$-point increase), stable, or improved ( $\geq 0.5$-point decrease) from baseline EDSS; mean change from baseline in MSFC and MSFC plus SLCLA scores and their components; and proportions worsened $(\geq 0.5 \mathrm{SD}$ decrease), stable, or improved ( $\geq 0.5 \mathrm{SD}$ increase) from baseline MSFC scores.

Additional analyses included integrated disability score of area under the curve (AUC $C^{\text {SUM }}$ and AUC CHANGE as previously described) ${ }^{21}$ for EDSS from quarterly visits over 2 years (considered more sensitive than CDI Kaplan-Meier analysis ${ }^{21}$ and odds ratios (ORs) for improvement vs stability or worsening on individual EDSS functional systems (visual [optic], brainstem, pyramidal, cerebellar, sensory, bowel/bladder, and cerebral [mental]) from baseline to month 24 . To determine whether disability improvement was confounded by recovery from recent relapse, we compared mean EDSS change from baseline to month 6 in patients with and without recent prestudy relapse (i.e., $\leq 3$ months before first study treatment). To determine dependence of disability improvement on relapse suppression by alemtuzumab, ${ }^{22}$ we compared mean EDSS change from baseline to month 6 in patients with and without early on-study relapse (i.e., relapse [per protocol definition] $\leq 6$ months after first treatment). ${ }^{22}$ Risk of disability progression based on $\geq 20 \%$ or $\geq 15 \%$ changes from baseline on $\geq 1$ MSFC component sustained for $\geq 6$ months was also assessed. ${ }^{18,23}$

Statistical analyses. Kaplan-Meier analyses were used to estimate risk for 3-month CDI (post hoc analysis) and 6-month CDI and risk for achieving specific ( $\geq 20 \%$ or $\geq 15 \%$ ) MSFC improvement or worsening thresholds. Hazard ratios (HRs) and $p$ values were generated using proportional hazards regression with covariate adjustment for geographic region and, for CDI endpoints, stratification by baseline EDSS. Integrated disability score of AUC for EDSS to 2 years (post hoc analysis) was calculated using the trapezium rule with EDSS score at all preplanned scheduled visits. ${ }^{21}$ EDSS AUC analysis used ranked 
analysis of covariance (ANCOVA) models with baseline EDSS and geographic region as covariates.

Changes from baseline on MSFC component $Z$ scores, overall MSFC score, and MSFC plus SLCLA scores were analyzed using the Wei-Lachin test and mixed model for repeated measures analyses with time-by-treatment interaction and covariate adjustment for geographic region and baseline score. The nonparametric Wei-Lachin multivariate test is used with repeated measures data using change from baseline at different timepoints to determine differences in score distribution over time between treatment groups. ${ }^{24}$ SLCLA was analyzed by ranked ANCOVA with covariate adjustment for geographic region and baseline score. Proportional odds models with covariate adjustment for geographic region and baseline EDSS or MSFC scores were used to analyze proportion worsened, stable, or improved on EDSS and MSFC. Odds of improvement vs stability or worsening on individual EDSS functional systems were determined with covariate adjustment for geographic region and baseline EDSS score.

Reported $p$ values are nominal and not adjusted for multiple comparisons.

Figure 1 Expanded Disability Status Scale (EDSS)-based improvement or worsening

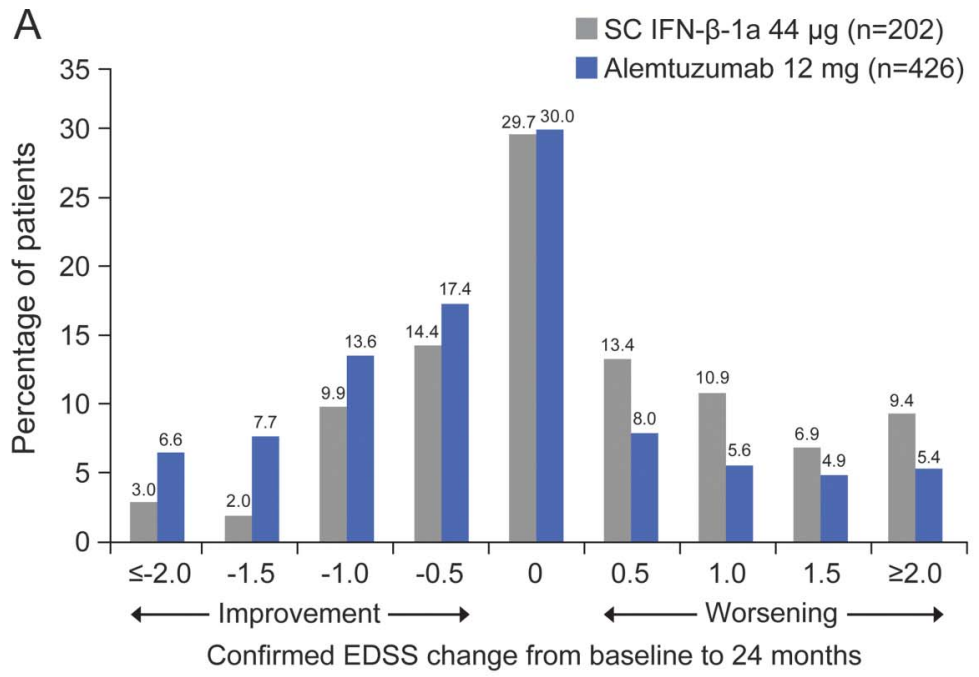

B

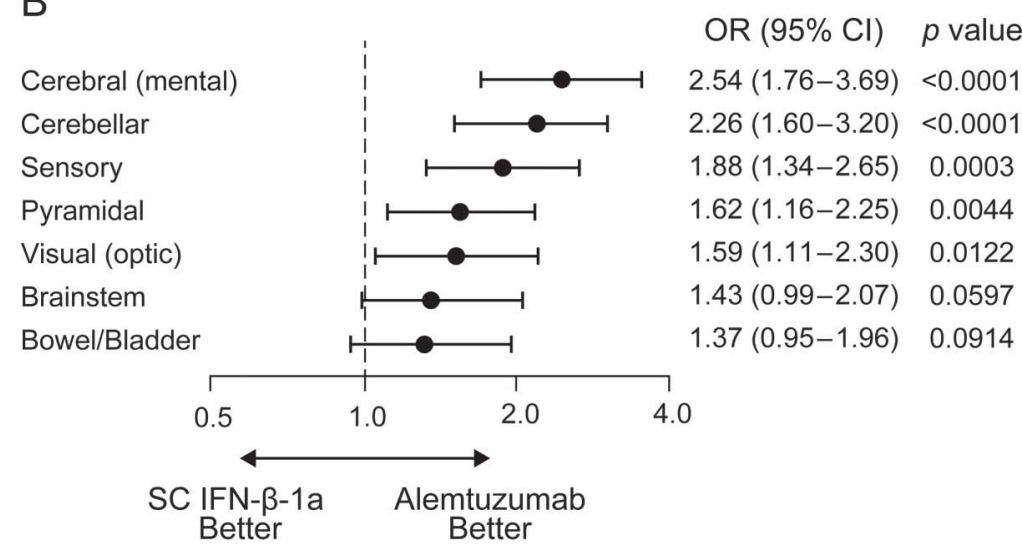

(A) Distribution of confirmed EDSS change from baseline to month 24 shown in half-point increments for alemtuzumab patients compared with subcutaneous interferon- $\beta$ - 1 a (SC IFN- $\beta$-1a) patients. (B) Odds for improvement vs remaining stable or worsening with respect to the different functional systems of the EDSS at month $24 . \mathrm{Cl}=$ confidence interval; $\mathrm{OR}=$ odds ratio of being improved vs stable or worsened.
Classification of evidence. This analysis examined whether alemtuzumab treatment slows disability accumulation and improves preexisting disability compared with SC IFN- $\beta-1 \mathrm{a}$ in patients with RRMS with an inadequate response to prior therapy. The results represent Class I evidence because of several elements of study design. Masked raters were used for study assessments related to key efficacy endpoints (e.g., EDSS for disability and relapse, MSFC, Sloan charts). Furthermore, randomization was performed such that the baseline characteristics were comparable between treatment arms.

Standard protocol approvals, registrations, and patient consents. This trial is registered with ClinicalTrials.gov (NCT00548405). All procedures were approved by local institutional ethics review boards of participating sites. Patients provided written informed consent.

RESULTS In total, 202 and 426 CARE-MS II patients were randomized to SC IFN- $\beta$-1a $44 \mu \mathrm{g}$ and alemtuzumab $12 \mathrm{mg}$, respectively. ${ }^{12}$ Baseline demographic and clinical characteristics were equivalent between treatment groups, as previously reported. ${ }^{12}$ Percentage of patients with recent prestudy relapse was also equivalent between groups (alemtuzumab, 32\%; SC IFN- $\beta-1 \mathrm{a}, 33 \%)$.

EDSS-based disability outcomes. From baseline to month 24, alemtuzumab patients were more likely than SC IFN- $\beta$-1a patients to show EDSS improvement $(p<0.0001$; figure 1A). Odds of improvement in all 7 EDSS functional systems were also greater for alemtuzumab than SC IFN- $\beta$-1a (figure 1B), reaching statistical significance in 5 domains (cerebral, cerebellar, sensory, pyramidal, and visual).

Alemtuzumab patients were more than twice as likely as SC IFN- $\beta$-1a patients to experience 3-month CDI $(34.7 \%$ vs $19.4 \%, p=0.0003$ [HR $=2.13]$ ), consistent with previously reported 6-month CDI data (28.8\% vs $12.9 \%, p=0.0002$ [HR $=2.57]$; figure 2). ${ }^{12}$ Among patients with baseline EDSS $\geq 3.0$, the proportion of patients with 6-month CDI was also significantly greater with alemtuzumab than SC IFN$\beta$-1a (35.4\% vs $15.3 \% ; p=0.0005$ [HR $=2.76])$. After stratification by presence or absence of prior IFN use, 6-month CDI remained consistently more likely with alemtuzumab vs SC IFN- $\beta$ - 1 a both for patients with prior IFN use (approximately $81 \%$ of patients originally investigated in each of the 2 on-study treatment arms, $28.4 \%$ vs $12.7 \%, p=0.0006[\mathrm{HR}=$ $2.64]$ ) and patients without prior IFN use (only around $19 \%$ of patients in each group, $30.5 \%$ vs $13.9 \%, p=$ $0.0542[\mathrm{HR}=3.01]$ ).

Alemtuzumab showed beneficial effect over SC IFN$\beta-1 \mathrm{a}$ in integrated disability score AUC ${ }^{\mathrm{CHANGE}}$ (mean [SD] $-2.3[18.45]$ vs 2.9 [16.84]; $p=0.0016$ ) and AUC $^{\mathrm{SUM}}$ analysis (62.8 [31.02] vs 64.8 [32.27]; $p=$ $0.0114)$.

Alemtuzumab patients had comparable mean EDSS improvement from baseline to month 6 in 


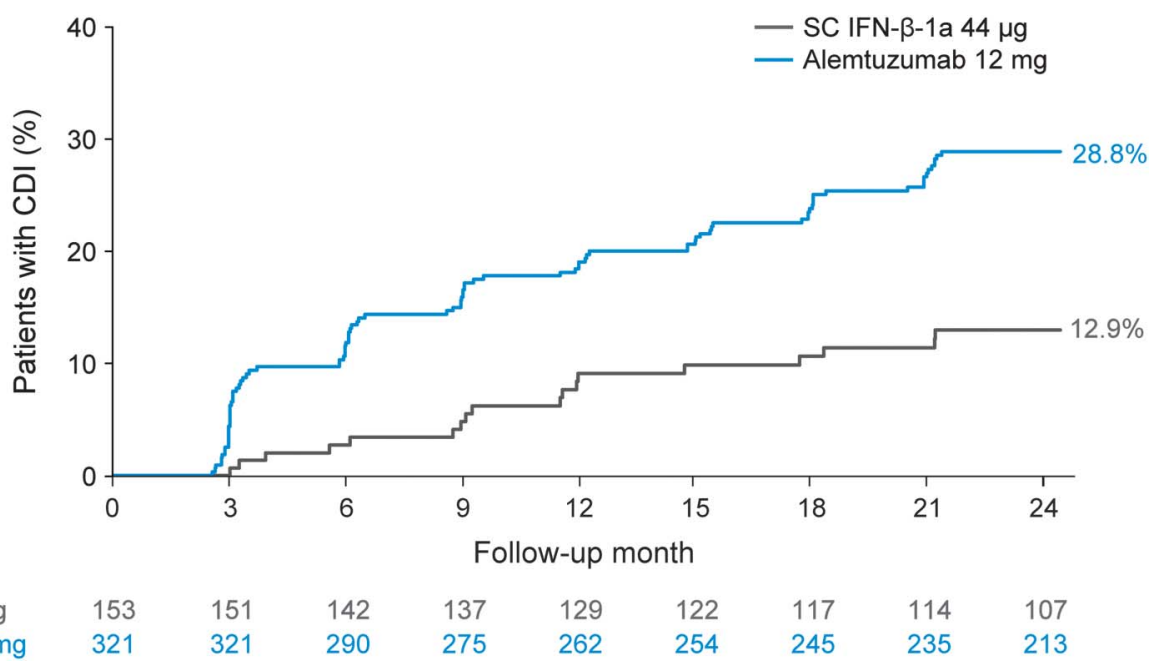

Number at risk

SC IFN- $\beta-1$ a $44 \mu \mathrm{g}$

Alemtuzumab $12 \mathrm{mg}$

$\begin{array}{ll}151 & 142 \\ 321 & 290\end{array}$

Kaplan-Meier estimates of risk for 6-month CDI with stratification by baseline Expanded Disability Status Scale (EDSS) Only patients with baseline EDSS $\geq 2.0$ were included in the analyses of CDI; 154 (alemtuzumab, $n=105 ;$ subcutaneous interferon- $\beta-1 a$ [SC IFN- $\beta-1 a$ ], $n=49$ ) patients were excluded from the analysis for not meeting this criterion.

cohorts with or without relapse within 3 months before initiating treatment (mean change -0.1 in both relapse groups), indicating that disability improvement did not merely reflect recovery from recent relapse. SC IFN- $\beta$-1a patients experienced worsened EDSS score from baseline to month 6 (mean change +0.21 and +0.14 in cohorts with or without recent pretreatment relapse, respectively); between-group differences were significant in both cohorts (recent pretreatment relapse, $p=0.0203$; no recent pretreatment relapse, $p=0.0065$ ).

Among patients without recent pretreatment relapse, significantly greater proportions experienced 3-month $(33.8 \%$ vs $15.2 \%, p=0.0004)$ and 6month CDI $(28.8 \%$ vs $9.2 \%, p=0.0002)$ with alemtuzumab vs SC IFN- $\beta$-1a over 24 months.

In patients with early on-study relapse, mean EDSS scores increased from baseline to month 6 with both treatments (alemtuzumab, 0.44; SC IFN- $\beta-1 \mathrm{a}, 0.37$; difference $0.07 ; p=0.7243$ ). Alemtuzumab-treated patients without early on-study relapse had improved 6-month EDSS scores; SC IFN- $\beta$-1a-treated patients showed worsening (difference $-0.23 ; p=0.0041$ ).

MSFC-based outcomes. The likelihood of 6-month confirmed improvement in MSFC score from baseline to month 24 was greater for alemtuzumab than SC IFN- $\beta$-1a (OR [95\% confidence interval] 1.80 [1.06, 3.08]; $p=0.0300)$. SC IFN- $\beta$-1a patients were significantly more likely than alemtuzumab patients to experience worsening MSFC (sustained for 6 months) at the $\geq 15 \%$ worsening threshold $(27.58 \%$ vs $18.66 \%$, $p=0.0143$; figure $3 \mathrm{~A}$ ). At the $\geq 20 \%$ threshold, the proportion who experienced worsening MSFC was numerically higher with SC IFN- $\beta$ - 1 a vs alemtuzumab, but the difference was not statistically significant (19.64\% vs $13.48 \%, p=0.0606)$.

Among MSFC components (figure 3, B-D), the greater benefit seen at month 24 with alemtuzumab vs SC IFN- $\beta$ - 1 a reached statistical significance for the 9-HPT ( $p=0.0007)$.

SLCLA-based outcomes. Alemtuzumab patients had more favorable visual outcomes than those receiving SC IFN- $\beta$-1a. Compared with baseline, visual acuity in alemtuzumab patients was stable at $2.5 \%$ contrast (month 12 change from baseline: 0.00; month 24: -0.01 ; both $p=$ not significant) and at $100 \%$ contrast (month 12: -0.06 ; month 24 : -0.04 ; both $p=$ not significant). SC IFN- $\beta-1 \mathrm{a}-$ treated patients had a significant decline in visual acuity from baseline to month 12 and from baseline to month 24 at $1.25 \%$ contrast (month 12 : -0.25 ; month 24: -0.19 ; both $p<0.01$ ) and $2.5 \%$ contrast (month 12: -0.20 ; month 24: -0.21 ; both $p<0.001)$, and $100 \%$ contrast for month 24 $(-0.16 ; p=0.0105)$. Differences between treatment groups were significant at $2.5 \%$ contrast (month 12: $p=0.0005$; month 24: $p=0.0014$ ) and at month 12 at $1.25 \%$ contrast $(p=0.0005)$. For MSFC plus SLCLA, alemtuzumab-treated patients significantly improved from baseline to month $12(0.04[p=0.0396])$; the score at month 24 increased from but did not differ from baseline (0.04 $[p=0.0787])$. SC IFN- $\beta$-1a-treated patients did not improve from baseline (month 12 : $-0.04[p=0.1600]$; month 24: $-0.06[p=$ $0.0876])$. The difference between treatment groups was significant at month 12 and month 24 (both $p<0.02$; figure $3 \mathrm{E})$. 
A. MSFC worsening $\geq 15 \%$

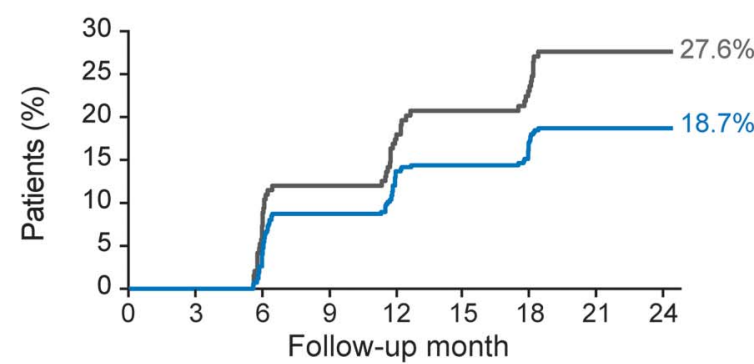

Number at risk

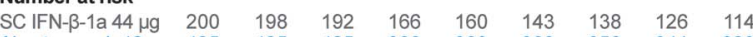

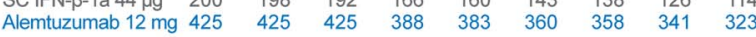

\section{Timed 25-Foot Walk}

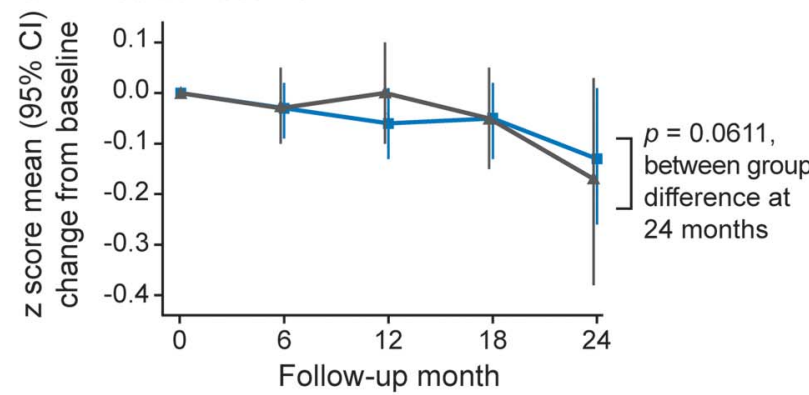

Number of patients

SC IFN-B-1a 44 $\mu \mathrm{gg} \quad 199 \quad 193 \quad 183 \quad 175 \quad 171$

$\begin{array}{llllll}\text { Alemtuzumab } 12 \mathrm{mg} & 425 & 421 & 413 & 398 & 402\end{array}$

E. MSFC + SLCLA (1.25\%)

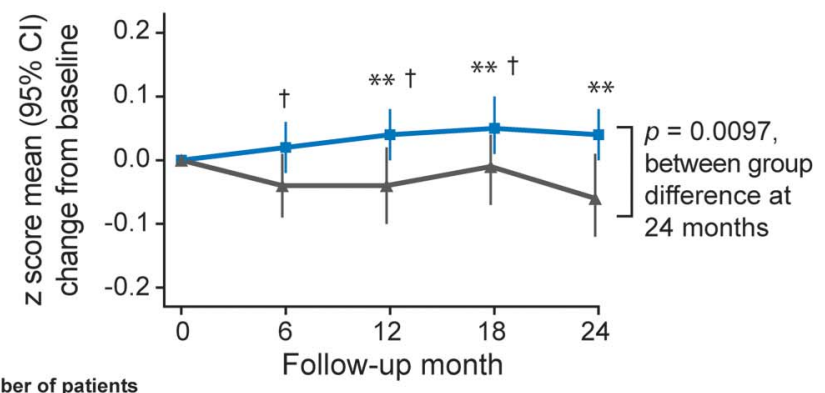

B. 9-Hole Peg Test

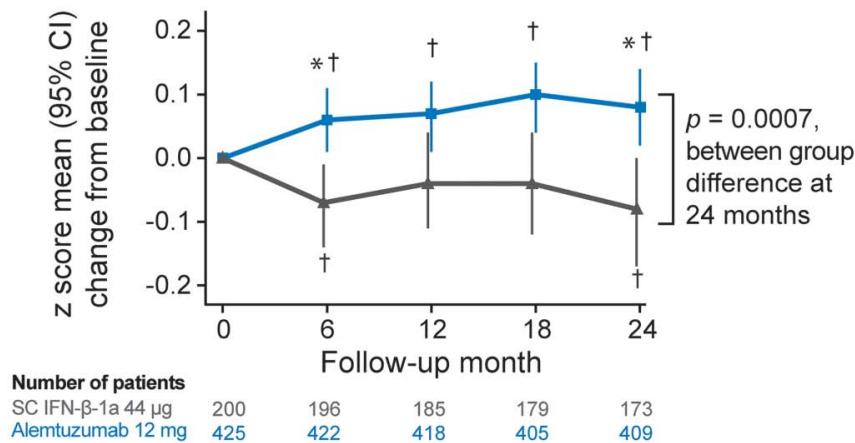

D. PASAT-3

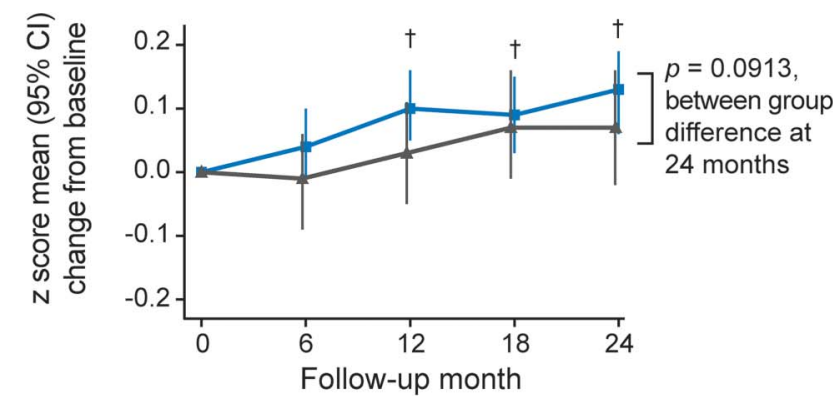

Number of patients

$\begin{array}{llllll}\text { SC IFN-B-1a 44 } \mu \mathrm{gg} & 199 & 195 & 184 & 179 & 173\end{array}$

$\begin{array}{llllll}\text { Alemtuzumab } 12 \mathrm{mg} & 423 & 419 & 417 & 401 & 408\end{array}$

$\begin{array}{llllll}\text { SC IFN-B-1a } 44 \mu \mathrm{g} & 164 & 156 & 149 & 144 & 140\end{array}$

$\begin{array}{llllll}\text { Alemtuzumab } 12 \mathrm{mg} & 348 & 348 & 342 & 329 & 337\end{array}$

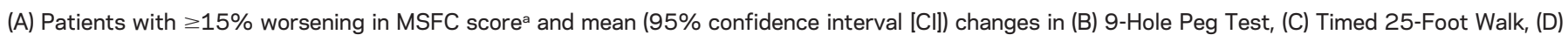

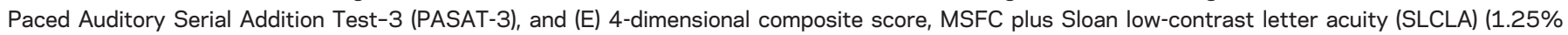

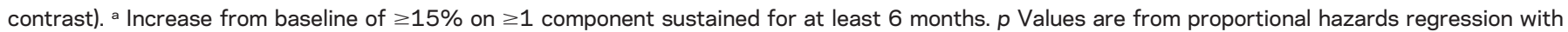

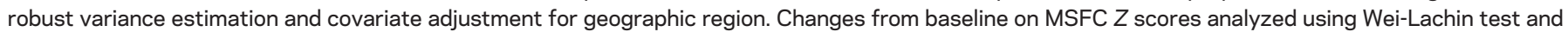

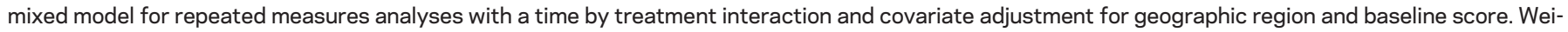

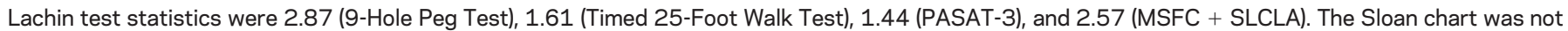

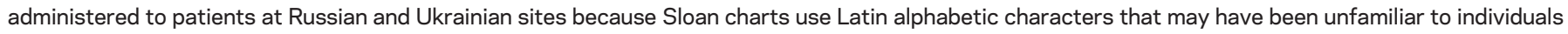

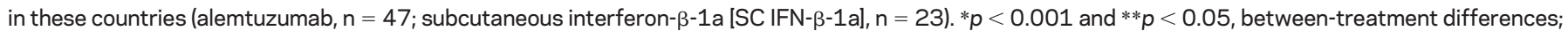
${ }^{+} p<0.05$, within-treatment change from baseline.

DISCUSSION Chronic disability plays a major role in the disease burden of MS. Current treatments may delay or prevent further increases in disability. However, few data exist concerning the ability of current treatments to help restore function over time in patients with previously acquired neurologic impairments, ${ }^{2,15}$ and there is a corresponding need for suitable metrics and analytic methods to reflect this novel outcome. Alemtuzumab was more effective than SC
IFN- $\beta$ - $1 \mathrm{a}$ at improving disability outcomes, significantly reducing the risk of 6-month CDW, and increasing 6-month CDI. ${ }^{12}$ The clinical efficacy of alemtuzumab vs SC IFN- $\beta$-1a was maintained regardless of the type of prior DMTs (i.e., IFN$\beta-1 \mathrm{a}$, IFN- $\beta-1 \mathrm{~b}$, or GA). ${ }^{12}$ The current analysis demonstrates that, in patients with RRMS with an inadequate response to prior DMTs, alemtuzumab provides greater recovery of function across several 
disability measures than SC IFN- $\beta-1 \mathrm{a}$. The use of this active comparator in the CARE-MS studies set a high threshold for superiority compared with placebo-controlled studies of other DMTs.

The findings of EDSS improvement from baseline to month 24 in nearly half of the alemtuzumabtreated patients, with improvements in all 7 EDSS functional domains, suggest that such disabilities may often be reversible (at least partially) in patients with active RRMS if they receive suitable therapy, irrespective of the type of baseline functional deficit. Favorable disability outcomes were not directly attributable to relapse suppression since, in the absence of early on-study relapse, EDSS scores improved in alemtuzumab-treated patients but deteriorated in those treated with SC IFN- $\beta$-1a. Alemtuzumab also demonstrated significant improvements from baseline vs SC IFN- $\beta$ - 1 a in mean EDSS AUC; this measure is less impacted than Kaplan-Meier analysis by transient fluctuations in EDSS scores typically observed in patients with RRMS. ${ }^{21}$ Another approach reported here is the relatively new outcome measure of CDI, which we first defined in our post hoc analysis of the phase 2 CAMMS223 trial. Rather than utilizing group means, CDI captures sustained and clinically meaningful EDSS score changes in individual patients, and thus has a simple clinical interpretation. By requiring repeated confirmation of EDSS change, it is resistant to transient fluctuations compared with singletimepoint analyses. Furthermore, this outcome only includes patients who have at least minimal preexisting neurologic impairment. ${ }^{11}$ Collectively, alemtuzumabassociated functional recovery reflected in a variety of EDSS-based measures represents an important, clinically meaningful benefit beyond slowing or preventing neurologic deterioration.

When assessing disability progression in MS, sensitivity to change can be enhanced by combining different outcome measures. ${ }^{14}$ The EDSS is the most familiar and commonly used neurologic disability index in MS trials, but has been criticized for its emphasis on ambulation and insensitivity to other disability components (e.g., cognition), especially at lower scores. ${ }^{13}$ The MSFC, which includes assessment of cognition, was selected to supplement the EDSS. ${ }^{16}$ From baseline to month 24, improvements in MSFC and MSFC plus SLCLA scores were significantly greater with alemtuzumab vs SC IFN- $\beta$ - 1 a. Previously, MSFC worsening $(\geq 15 \%$ and $\geq 20 \%$ worsening from baseline on at least one MSFC component and sustained for $\geq 3$ months) was shown to correlate with EDSS, relapse rates, and some patientreported outcomes; $15 \%$ was the more sensitive threshold to treatment effects. ${ }^{18}$ Alemtuzumab demonstrated significant benefit over SC IFN- $\beta$-1a at the $15 \%$ threshold over $\geq 6$ months. The effect of alemtuzumab differed across MSFC component scores; the strongest treatment effects were observed on the 9-HPT, indicating that improvement in upper limb function with alemtuzumab drove improvement on the MSFC composite score.

The analyses supporting DMT-induced improvement in preexisting disability reported here were prespecified and should be evaluated in the context of other published trials. The present findings are consistent with a post hoc analysis of CAMMS223, ${ }^{22}$ which enrolled treatment-naive patients with RRMS. Improvements in preexisting disability were also reported from placebo-controlled but not active-controlled trials of natalizumab, and only using the 3-month-sustained (not 6-month) criterion, ${ }^{15}$ and from a placebocontrolled GA trial. ${ }^{2}$ In the present, active-controlled study, CDI was achieved by significantly more alemtuzumab-treated than SC IFN- $\beta$ - 1 - - treated patients using either 3-or 6-month confirmed criteria.

The mechanisms underlying the greater observed improvement in preexisting disability after alemtuzumab are uncertain. Improvement does not reflect the expected recovery from recent prestudy relapses. Moreover, the finding that mean disability did not improve with SC IFN- $\beta$-1a even among those who had no clinically evident inflammatory activity on study suggests that disability improvement after alemtuzumab is not fully explained by superior reduction of inflammation. However, alemtuzumab's more efficacious inhibition of CNS inflammation may provide a tissue environment that better supports endogenous remyelination and repair mechanisms. Another possible mechanism involves neurotrophic factors secreted by CNS-trafficking immune cells, which have been postulated to contribute to neuroprotection and remyelination in MS. ${ }^{25,26}$ In one study, immune cells repopulating after alemtuzumab treatment for MS secreted neurotrophic factors, including brain-derived neurotrophic factor and ciliary neurotrophic factor, after exposure to myelin basic protein in vitro. ${ }^{22}$ Further studies are necessary to confirm a role for neurotrophic mechanisms in the stabilization or improvement in disability observed in alemtuzumab-treated patients with MS.

Differences in timing, mode of administration, and side effect profiles for alemtuzumab and SC IFN- $\beta$-1a made a true double-blind design unfeasible, which may be considered a limitation of this study. However, to minimize potential bias, key efficacy assessments, including EDSS, MSFC, Sloan charts, and on-study relapses, were performed by trained evaluators blinded to treatment, and all suspected relapses were adjudicated by an independent, blinded relapse adjudication panel.

Alemtuzumab's clinical efficacy in CARE-MS II and associated greater beneficial effects than those of 
SC IFN- $\beta$-1a on disability outcomes should be considered in the context of the risks, including infusionassociated reactions, infections, and autoimmune adverse events. ${ }^{12,27}$ Measures to manage these potentially serious risks are essential for the safe use of alemtuzumab.

The outcomes presented here not only support alemtuzumab's ability to slow disability accumulation, but also demonstrate superior benefit in improving preexisting disability in patients with RRMS with an inadequate response to prior DMT. These data add to the body of evidence supporting a favorable benefit-risk profile of alemtuzumab in the treatment of RRMS.

\section{AUTHOR CONTRIBUTIONS}

Statistical analysis was performed primarily by Stephen L. Lake (Sanofi Genzyme, Cambridge, MA). G.G., J.A.C., A.J.C., H.-P.H., E.H., K.W.S., D.H.M., M.A.P., and D.A.S.C. contributed to study design, data collection, and writing and critical review of the manuscript, and approved the final submission draft. S.L.L. led the statistical support, contributed to the writing and critical review of the manuscript, and approved the final submission draft. S.M.K. provided editorial and medical writing support (assistance in drafting the manuscript, technical editing, copyediting, and responding to reviewers' comments).

\section{ACKNOWLEDGMENT}

Statistical support for response to reviewers' comments was provided by Karthinathan Thangavelu, PhD (Sanofi Genzyme, Cambridge, MA). Critical review of the manuscript was conducted by Aji Nair, PhD, who was employed at Sanofi Genzyme during the development of the manuscript. The CARE-MS II study was funded by Sanofi Genzyme and Bayer HealthCare Pharmaceuticals. Linda Kasten (Prometrika, LLC, Cambridge, MA) contributed to statistical analyses, which were funded by Sanofi Genzyme.

\section{STUDY FUNDING}

Supported by Sanofi Genzyme and Bayer HealthCare Pharmaceuticals.

\section{DISCLOSURE}

G. Giovannoni reports receiving compensation for consulting and receiving grant/research support from Abbvie, Bayer HealthCare Pharmaceuticals, Biogen, Canbex, Five Prime, GlaxoSmithKline, GW Pharma, Merck Serono, Novartis, Oxford PharmaGenesis, Protein Discovery Laboratories, Roche, Sanofi Genzyme, Synthon, Teva, and UCB. J. Cohen reports receiving personal compensation for consulting from Genentech, Novartis, Receptos, and Sanofi Genzyme, and speaking fees from Teva. A. Coles reports receiving consulting fees, lecture fees, and institutional grant support from Sanofi Genzyme. H.-P. Hartung reports receiving honoraria for consulting and speaking from Bayer HealthCare Pharmaceuticals, Biogen, CSL Behring, Grifols, Merck Serono, Novartis, Roche, and Sanofi Genzyme. E. Havrdova reports receiving honoraria and grant support from Actelion, Biogen, Merck Serono, Novartis, Roche, Sanofi Genzyme, and Teva and research support from the Ministry of Education, Czech Republic (project PRVOUK-P26/LF1/4). K. Selmaj reports receiving consulting and speaking fees from Biogen, Merck, Novartis, Roche, Sanofi Genzyme, and Synthon. D. Margolin reports receiving personal compensation as an employee of Sanofi Genzyme. S. Lake reports receiving personal compensation as an employee of Sanofi Genzyme. S. Kaup reports receiving personal compensation as an employee of Evidence Scientific Solutions when the work was conducted. M. Panzara reports receiving personal compensation as an employee of Sanofi Genzyme. D. Compston reports receiving consulting fees and grant support from Sanofi Genzyme and lecture fees from Bayer Schering Pharma on behalf of the University of Cambridge and personal remuneration for lecture fees from Sanofi Genzyme. Go to Neurology.org for full disclosures.

Received June 2, 2015. Accepted in final form July 7, 2016.

\section{REFERENCES}

1. Gold R, Kappos L, Arnold DL, et al. Placebo-controlled phase 3 study of oral BG-12 for relapsing multiple sclerosis. N Engl J Med 2012;367:1098-1107.

2. Johnson KP, Brooks BR, Cohen JA, et al. Copolymer 1 reduces relapse rate and improves disability in relapsingremitting multiple sclerosis: results of a phase III multicenter, double-blind placebo-controlled trial: The Copolymer 1 Multiple Sclerosis Study Group. Neurology 1995;45: 1268-1276.

3. Kappos L, Radue EW, O'Connor P, et al. A placebocontrolled trial of oral fingolimod in relapsing multiple sclerosis. N Engl J Med 2010;362:387-401.

4. O'Connor P, Wolinsky JS, Confavreux C, et al. Randomized trial of oral teriflunomide for relapsing multiple sclerosis. N Engl J Med 2011;365:1293-1303.

5. Polman CH, O'Connor PW, Havrdova E, et al. A randomized, placebo-controlled trial of natalizumab for relapsing multiple sclerosis. N Engl J Med 2006;354:899-910.

6. PRISMS (Prevention of Relapses and Disability by Interferon beta-1a Subcutaneously in Multiple Sclerosis) Study Group. Randomised double-blind placebo-controlled study of interferon beta-1a in relapsing/remitting multiple sclerosis. Lancet 1998;352:1498-1504.

7. The IFNB Multiple Sclerosis Study Group. Interferon beta- $1 \mathrm{~b}$ is effective in relapsing-remitting multiple sclerosis: I: clinical results of a multicenter, randomized, double-blind, placebo-controlled trial. Neurology 1993; 43:655-661.

8. Julian LJ, Vella L, Vollmer T, Hadjimichael O, Mohr DC. Employment in multiple sclerosis: exiting and re-entering the work force. J Neurol 2008;255:1354-1360.

9. Naci H, Fleurence R, Birt J, Duhig A. The impact of increasing neurological disability of multiple sclerosis on health utilities: a systematic review of the literature. J Med Econ 2010;13:78-89.

10. Rudick RA, Cutter G, Baier M, et al. Use of the Multiple Sclerosis Functional Composite to predict disability in relapsing MS. Neurology 2001;56:1324-1330.

11. Coles AJ, Fox E, Vladic A, et al. Alemtuzumab versus interferon beta-1a in early relapsing-remitting multiple sclerosis: post-hoc and subset analyses of clinical efficacy outcomes. Lancet Neurol 2011;10:338-348.

12. Coles AJ, Twyman CL, Arnold DL, et al. Alemtuzumab for patients with relapsing multiple sclerosis after diseasemodifying therapy: a randomised controlled phase 3 trial. Lancet 2012;380:1829-1839.

13. Hobart J, Freeman J, Thompson A. Kurtzke scales revisited: the application of psychometric methods to clinical intuition. Brain 2000;123:1027-1040.

14. Kragt JJ, Nielsen JM, van der Linden FA, Polman $\mathrm{CH}$, Uitdehaag BM. Disease progression in multiple sclerosis: combining physicians' and patients' perspectives? Mult Scler 2011;17:234-240.

15. Phillips JT, Giovannoni G, Lublin FD, et al. Sustained improvement in Expanded Disability Status Scale as a new efficacy measure of neurological change in multiple sclerosis: treatment effects with natalizumab in patients with relapsing multiple sclerosis. Mult Scler 2011;17:970-979. 
16. Cutter GR, Baier ML, Rudick RA, et al. Development of a Multiple Sclerosis Functional Composite as a clinical trial outcome measure. Brain 1999;122:871-882.

17. Fischer JS, Jak AJ, Kniker JE, Rudick RA, Cutter G. Administration and Scoring Manual for the Multiple Sclerosis Functional Composite (MSFC). New York: National Multiple Sclerosis Society; 2001.

18. Rudick RA, Polman CH, Cohen JA, et al. Assessing disability progression with the Multiple Sclerosis Functional Composite. Mult Scler 2009;15:984-997.

19. Talman LS, Bisker ER, Sackel DJ, et al. Longitudinal study of vision and retinal nerve fiber layer thickness in multiple sclerosis. Ann Neurol 2010;67:749-760.

20. Balcer LJ, Baier ML, Cohen JA, et al. Contrast letter acuity as a visual component for the Multiple Sclerosis Functional Composite. Neurology 2003;61:1367-1373.

21. Liu C, Blumhardt LD. Disability outcome measures in therapeutic trials of relapsing-remitting multiple sclerosis: effects of heterogeneity of disease course in placebo cohorts. J Neurol Neurosurg Psychiatry 2000;68: 450-457.
22. Jones JL, Anderson JM, Phuah CL, et al. Improvement in disability after alemtuzumab treatment of multiple sclerosis is associated with neuroprotective autoimmunity. Brain 2010;133:2232-2247.

23. Kragt JJ, van der Linden FA, Nielsen JM, Uitdehaag BM, Polman CH. Clinical impact of $20 \%$ worsening on Timed 25-Foot Walk and 9-Hole Peg Test in multiple sclerosis. Mult Scler 2006;12:594-598.

24. Lachin JM. Power and sample size evaluation for the McNemar test with application to matched case-control studies. Stat Med 1992;11:1239-1251.

25. Compston DA, Confavreux C, Lassmann H, et al. McAlpine's Multiple Sclerosis. 4th ed. London: Elsevier; 2006.

26. Kerschensteiner M, Gallmeier E, Behrens L, et al. Activated human $\mathrm{T}$ cells, B cells, and monocytes produce brain-derived neurotrophic factor in vitro and in inflammatory brain lesions: a neuroprotective role of inflammation? J Exp Med 1999;189:865-870.

27. Menge T, Stüve O, Kieseier BC, Hartung HP. Alemtuzumab: the advantages and challenges of a novel therapy in MS. Neurology 2014;83:87-97.

\section{Help Get the New Congress to Work for Neurology}

The 2016 election may bring about the most sweeping changes in Congress that we have seen in years, if not decades. Join your AAN colleagues at Neurology on the Hill from February 27-28, 2017, and help educate members of Congress so we can address critical health policy problems together. If selected, you will receive training to bring you up-to-date on key issues. Then, we will go to Capitol Hill for face-to-face meetings with congressional members and their staffs. The Academy will cover airfare expenses and hotel accommodations. There is a general registration fee of $\$ 150$, or $\$ 50$ for residents, fellows, and members residing in the Washington, DC, area. Encourage your colleagues to apply as well. Space is limited and fills quickly. Learn more and apply by November 20, 2016, at $A A N$.com/view/2017NOH.

\section{Increasing the Value of YOUR AAN Membership}

\section{FREE MOC Benefits Starting January 1, 2015}

You asked and we listened. As of January 1, 2015, your robust AAN membership package includes FREE* access to online learning programs designed specifically to help you take the necessary steps toward fulfilling your maintenance of certification (MOC) requirements as mandated by the ABPN: NeuroPI ${ }^{\text {SM }}$, NeuroSAE ${ }^{\circledR}$, NeuroLearn $^{\text {SM }}$.

Learn more at $A A N$.com/view/MOC

* \$0 purchase price excludes Student members and Nurse Practitioner/Physician Assistant members at the lower dues rate. Free access is limited to one course per program at a time. 


\section{Neurology}

Alemtuzumab improves preexisting disability in active relapsing-remitting MS patients Gavin Giovannoni, Jeffrey A. Cohen, Alasdair J. Coles, et al.

Neurology 2016;87;1985-1992 Published Online before print October 12, 2016 DOI 10.1212/WNL.0000000000003319

This information is current as of October 12, 2016

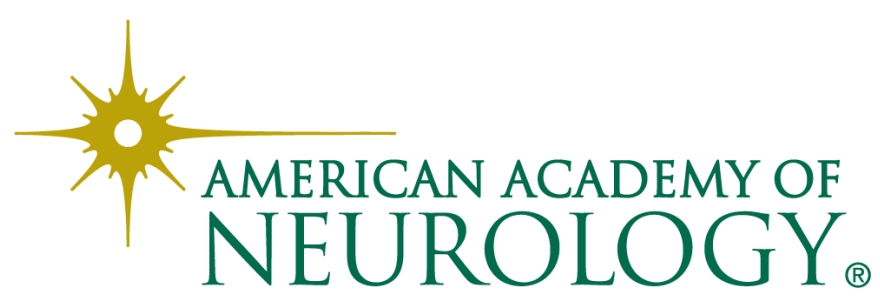




\section{Updated Information \& Services}

\section{Supplementary Material}

\section{References}

Citations

Subspecialty Collections

\section{Permissions \& Licensing}

Reprints including high resolution figures, can be found at: http://n.neurology.org/content/87/19/1985.full

Supplementary material can be found at: http://n.neurology.org/content/suppl/2016/10/12/WNL.0000000000003 319.DC1

http://n.neurology.org/content/suppl/2016/11/07/WNL.0000000000003 319.DC2

This article cites 25 articles, 7 of which you can access for free at: http://n.neurology.org/content/87/19/1985.full\#ref-list-1

This article has been cited by 4 HighWire-hosted articles: http://n.neurology.org/content/87/19/1985.full\#\#otherarticles

This article, along with others on similar topics, appears in the following collection(s):

\section{Autoimmune diseases}

http://n.neurology.org/cgi/collection/autoimmune_diseases

\section{Class I}

http://n.neurology.org/cgi/collection/class_1

Clinical trials Randomized controlled ( $\mathbf{C}$ ONSORT agreement)

http://n.neurology.org/cgi/collection/clinical_trials_randomized_control led_consort_agreement

Multiple sclerosis

http://n.neurology.org/cgi/collection/multiple_sclerosis

Information about reproducing this article in parts (figures,tables) or in its entirety can be found online at:

http://www.neurology.org/about/about_the_journal\#permissions

Information about ordering reprints can be found online:

http://n.neurology.org/subscribers/advertise

Neurology ${ }^{\circledR}$ is the official journal of the American Academy of Neurology. Published continuously since 1951, it is now a weekly with 48 issues per year. Copyright @ 2016 American Academy of Neurology. All rights reserved. Print ISSN: 0028-3878. Online ISSN: 1526-632X.

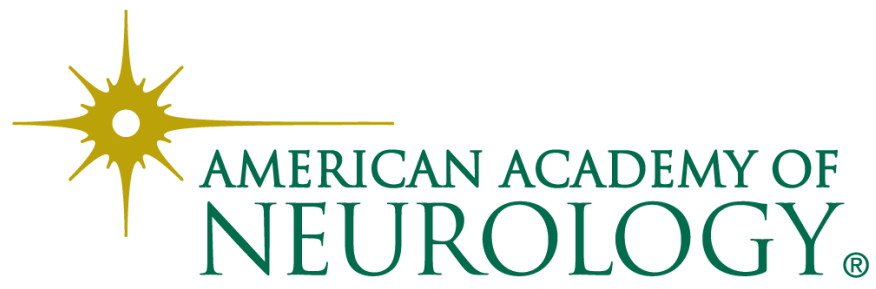

